$$
\text { DCE/PCH12\%2-.TH }
$$

RHEOLOGICAL PROPERTIES ESSENTIAL FOR THE ATOMIZATION OF COAL WATER SLURRIES (CWS).

Quarterly Progress Report June 15, 1992-Septenber 15, 1992

DOE/PC/91292--T4

DE93 006004

FRANK OHENE

Department of Chemistry Grambling State University Grambling, LA 71245

Technical Project officer

U. S. Department of Energy Pittsburgh Technology Energy Center

P. O. Box 10940

Pittsburgh, PA 15236

Work Performed for the Department of Energy Under contract \#DE-FG22-91PC91292

\title{
DISCLAIMER
}

"This report was prepared as an account of work sponsored by an agency of the United States Government. Neither the United states Government nor any agency thereof, nor any of their employees, makes any warranty, express of implied, or assumes any legal liability or responsibility for the accuracy, completeness, or usefulness of any information, apparatus, product, or process disclosed, or represents that its use would not infringe privately owned rights. Reference therein to any specific commercial product, process or service by tradename, trademark, manufacturer, or otherwise, does not necessarily constitute or imply its endorsement, recommendation, or favoring by the United states Government or any agency thereof. The views and opinions of the author expressed herein do not necessary state or reflect those of the United States or Government or any agency thereof." 


\section{SCT 251996}

OVERALL OBJECTIVE:

The overall objective of this project is to perform experiments to understand the effect of high shear and extensional properties on the atomization of coal-water slurries (CWS). In the atomization studies, the mean drop size of the cWs sprays will be determined at various air-to CWS. A correlation between the extensional and high shear properties, particle size distributions and the atomization will be made in order to determine the influence of these parameters on the atomization of CWS.

\section{Work Done}

During the past quarter, several experimental studies on pressure dependent atomization of Coal-water slurries and simulated fluids were performed. Also surface tension, elastic, high and low shear viscosities were performed. These tests were performed to initiate the understanding of the fundamental parameters that govern the atomization process of CWS.

\section{Surface Tension}

The influence of surface tension on sauter mean Diameter (SMD) has been discussed by Lefebre [1]. Thus, to test the significance of this parameter on atomization, the surface tension of several diluted concentrations of corn syrup were measured using Fisher morel du-Nuoy Tensiomat, model 21. The tensiomat's performance was initially verified by determing the surface tension of distilled water. Excellent agreement was obtained between the measured value and the literature value of 72 dynes/cm. The results of the surface tension measurements as well as, the viscosity and the densities 
are as shown in Table 1.

\section{Rheological properties}

The Rheological properties of the corn syrup solutions were determined using a Haake RV-20 rheometer. The corn syrup solutions were found to be Newtonian and the viscosities ranged from 709 mPas.s to 120 mpas.s, dependeing on the concentration. The flow curves for $100 \%$ and $80 \%$ corn syrup solutions are as shown in Figures 3 and 4 . The densities of these solutions were found to be in the range of 1.37 to $1.02 \mathrm{gm} / \mathrm{mL}$ (Table 1). The density of the coal-water slurries used had densities of between $1.12 \mathrm{gm} / \mathrm{mL}$ and $1.26 \mathrm{gm} / \mathrm{ml}$.

In order to understand the CWS atomization behavior, it is neccessary to understand the flow behavior of the cWs. A low shear flow behavior of $66 \%$ and $61 \%$ CWS (PSOC-1527) containg $0.5 \% A-23$ coal weight as additive, and high shear flow behavior of $61 \%$ (PSOC1527) slurry used in the atomization studied are as shown in Figures 5-8. The high shear was run on Pen-Kem HVA-6 capillary rheometer (Fiure 8). This instrument was evaluated and found to be excellent in the study of high shear behavior of the CWS. Also, a viscoelastic measurements of the CWS was made (Figure 7). The slurry exhibited a Newtonian flow in the shear rate region of between $8.89 \times 10^{3} 1 / \mathrm{s}$ and $1.29 \times 10^{5} 1 / \mathrm{s}$ (Figure 7 and Table 2.) The viscoelastic measurement show that tire slurry has a considerable elastic component (Figure 8).

Several experiments on the high shear and the viscoelastic behavior will be performed during the next quarter in order to 
relate the data to the Sauter Mean Diameter (SMD).

Atomization studies

Atomization studies w..e performed at Adelphi University. The initial tests were performed to compare and optimize conditions neccessary for the CWS atomization. A video camera system and a Malvern 2600 particle size analyzer and a Dalvan Airo Nozzle were used to provide information about the spray characteristics, including drop size distribution, mean median size distribution and spray velocity. The source of atomizing air used was the house air system, which delivers air at pressures up to a maximum of 85 psig. The atomizing air passes through a filter and a flowmeter before it enters the atomizer.

The atomization results of the corn syrup solutions and the CWS are as shown in Figures 1 and 2. The Sauter Mean Diameter (SMD) obtained for each concentration is as listed in Figures 1 and 2 . In the corn syrup atomization studies, the SMD was found to decrease with decrease in the corn syrup concentration. The A/F ratio was maintained at 0.2 in this studies. The density and surface tension of the solution were also found to decrease with concentration. In the CWS atomization studies, the A/F ratio was increased to 0.4 due to initial clogging of the nozzle at the low $A / F$ ratio. This increase was neccessary to effect a constant stream of fine spray production. This is an indication that the atomization of the cWs is dependent on the $A / F$ ratio.

The CWS used exhibited a pseudoplastic with yield flow behavior in the low shear reyime, whereas the corn syrup solutions 
exhibited a Newtonian flow behavior (Figure 3-6). The observed differences in fine spray obtained for the CWS and the corn syrup solutions at $A / F$ ratio of 0.2 , is probably due to differences in their flow behaviors.

Further experiments on corn syrup solutions containing polymer additives, will be performed in the subsquent quarters to determine the effect of the flow behavior (consistency index, density, A/F ratio and surface tension) of the corn syrup solutions isn atomization. Varying concentrations of xantham gum will be added to the corn syrup solutions and changes in the flow consistency index noted as a function of Xantham gum concentration. 


\begin{tabular}{llll} 
& \multicolumn{3}{c}{ Table 1} \\
Corn Syrup & Density & Surface Tension & Viscosity \\
Concentration $(\%)$ & $(\mathrm{gm} / \mathrm{mL})$ & $($ dynes/cm) & (mPa.S) \\
100 & 1.37 & 80.64 & 750 \\
90 & 1.31 & 76.1 & 234 \\
80 & 1.26 & 73.8 & 196 \\
70 & 1.23 & 70.9 & 103 \\
60 & 1.19 & 59.8 & 72.4 \\
50 & 1.14 & 53.4 & 45.2 \\
30 & 1.08 & 51.2 & 34.2
\end{tabular}


TABI.E 2

\section{HIGH SHFER RHEOI,OGY DATA}

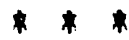

PA $\cap R$

$1 \div 1 \div 11 \quad 1 \ldots$
$H V A-6$

î miil
$191919 \%$

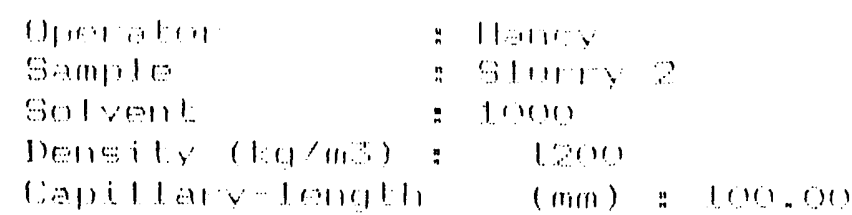

\author{
1. i. $10: 91111 \%$ \\ Homitier: mogrot

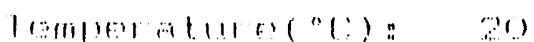

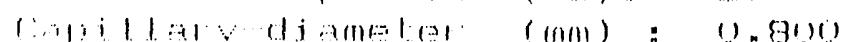

\section{$11 \% 19$}

$1,1,101 i$

No.

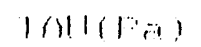

1nll con (19)

(i) $1(5)$

$1: 10(1)=)$

\begin{tabular}{|c|c|}
\hline 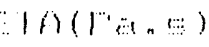 & lisyol. \\
\hline 4.0290 & 29 \\
\hline$\therefore 0.286$ & $4 \%$ \\
\hline 0.0248 & $9 \%$ \\
\hline$\therefore .096$ & $11 \%$ \\
\hline 9 (1261 & 193 \\
\hline$\because 4000$ & 210 \\
\hline 0 " 929 & $26 \%$ \\
\hline 0,95 & 5 \\
\hline$\because{ }_{n} 027 \%$ & $\therefore 60$ \\
\hline 1) 4966 & 465 \\
\hline
\end{tabular}

$\because-679+109$

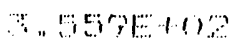

$\because .461 \%+02$

$\because 961 \% 10 \%$

1. 11.21010

1. $4941 \% 10 \%$

1. . $7918+10 \%$

$\because 18010$

$\therefore$ - 901010

$\because 4100$
$9.99010 \%$

1. 210101

$2.245+04$

$\therefore 94=10 \%$

1.211101019

a $69+91$

6.9211.01

Q 60,101

1.000100

1 - $29010+6$ $\operatorname{lv}(9)$

0.125

U. 01809

0.0445

0.0387

(1) 0257

(1). 0176

0. 01.4 .

(). $011 \%$

$0.019 \%$

0.0078 


\section{Reference}

1. Lefebvre, A. H., Atomization and Spray Technology, 3, (1987), $37-31$ 


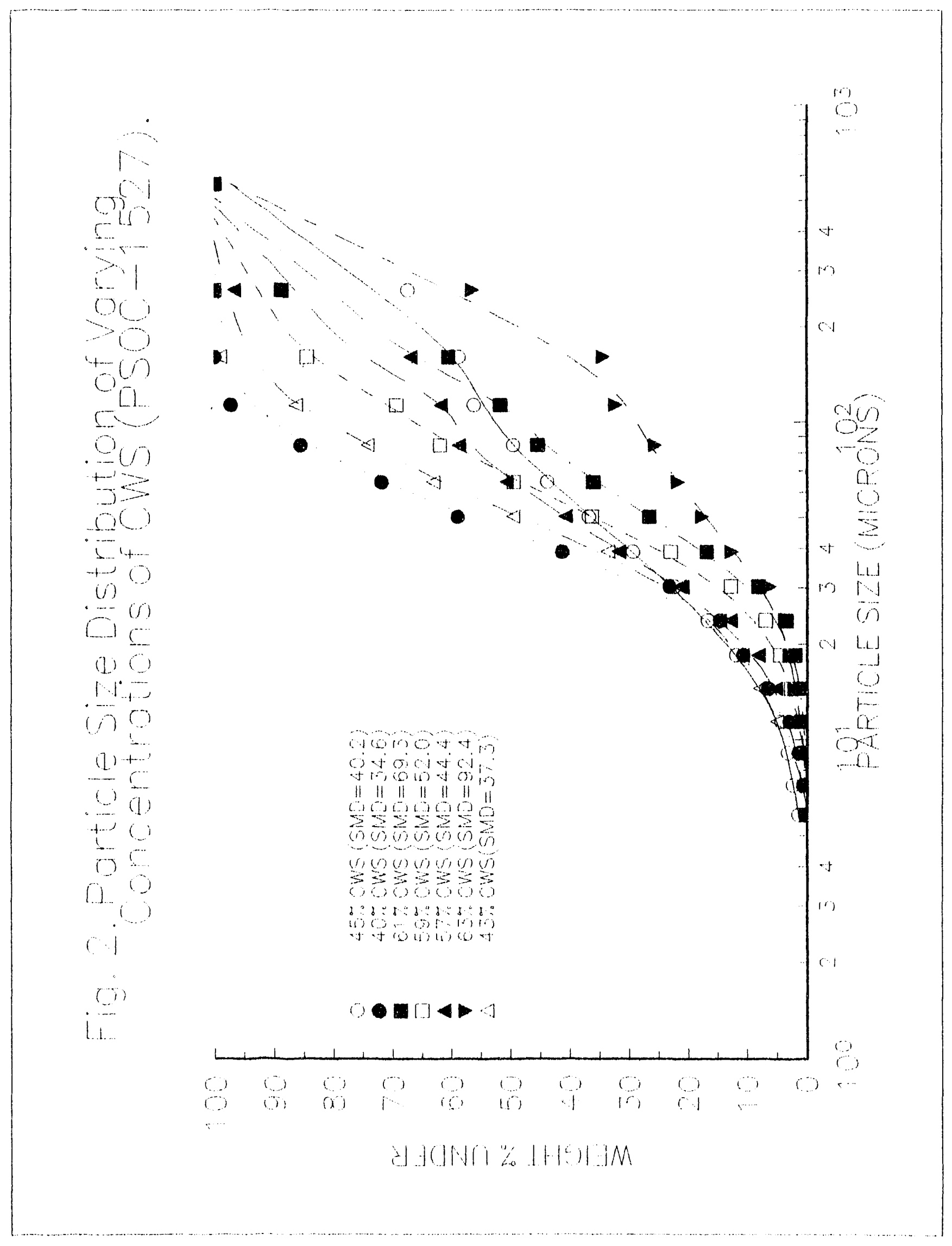

$\infty$ 


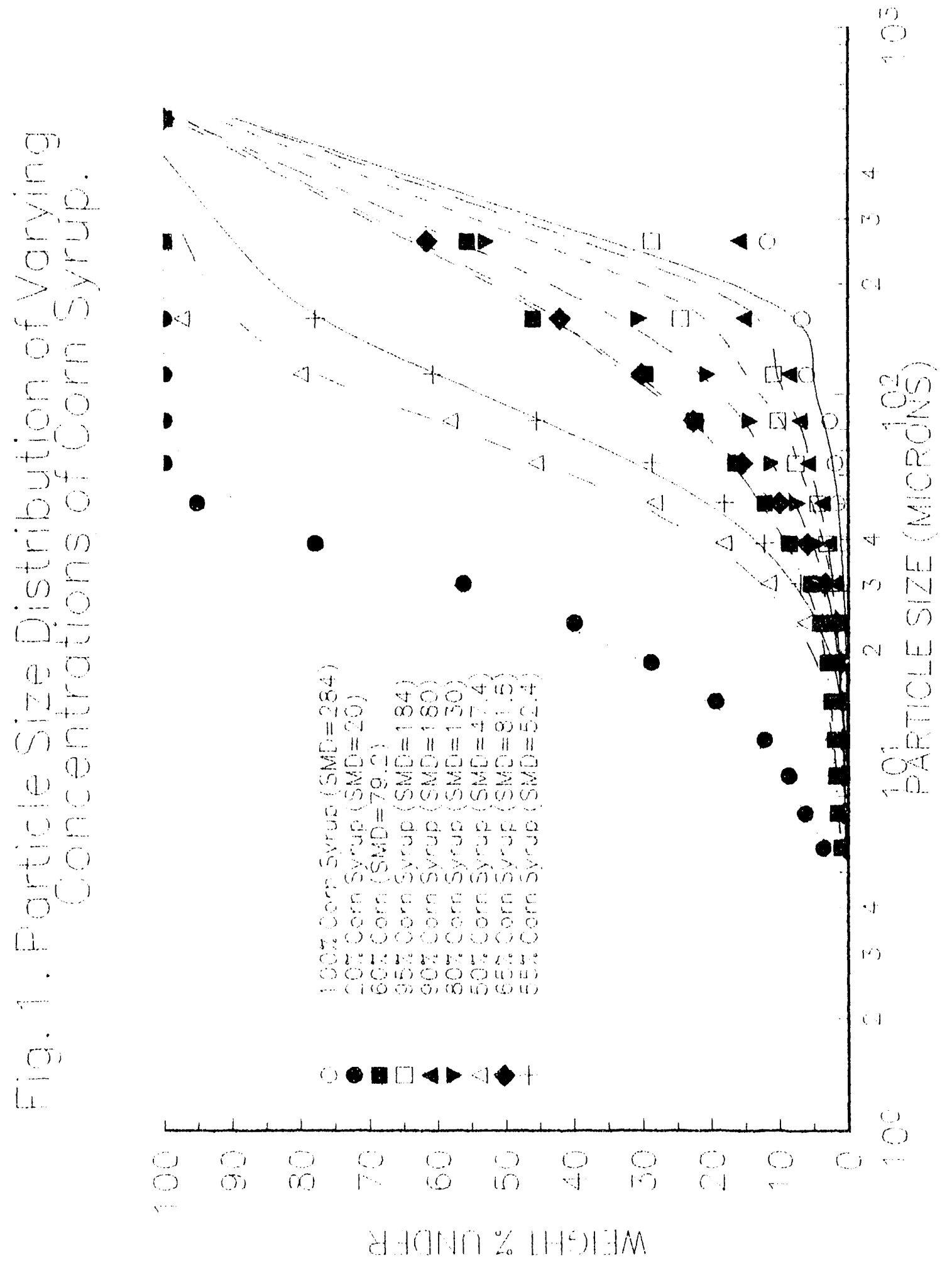




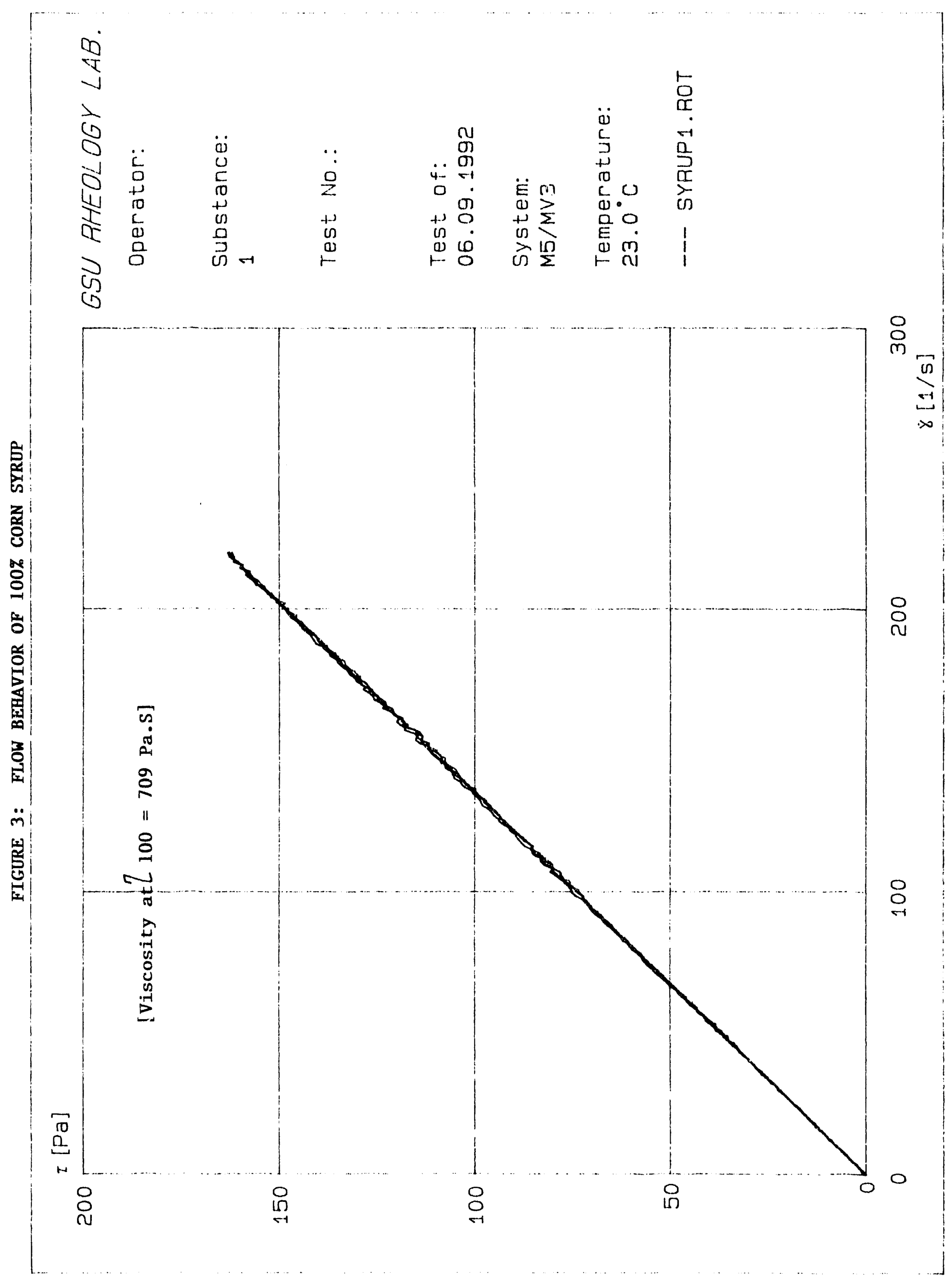




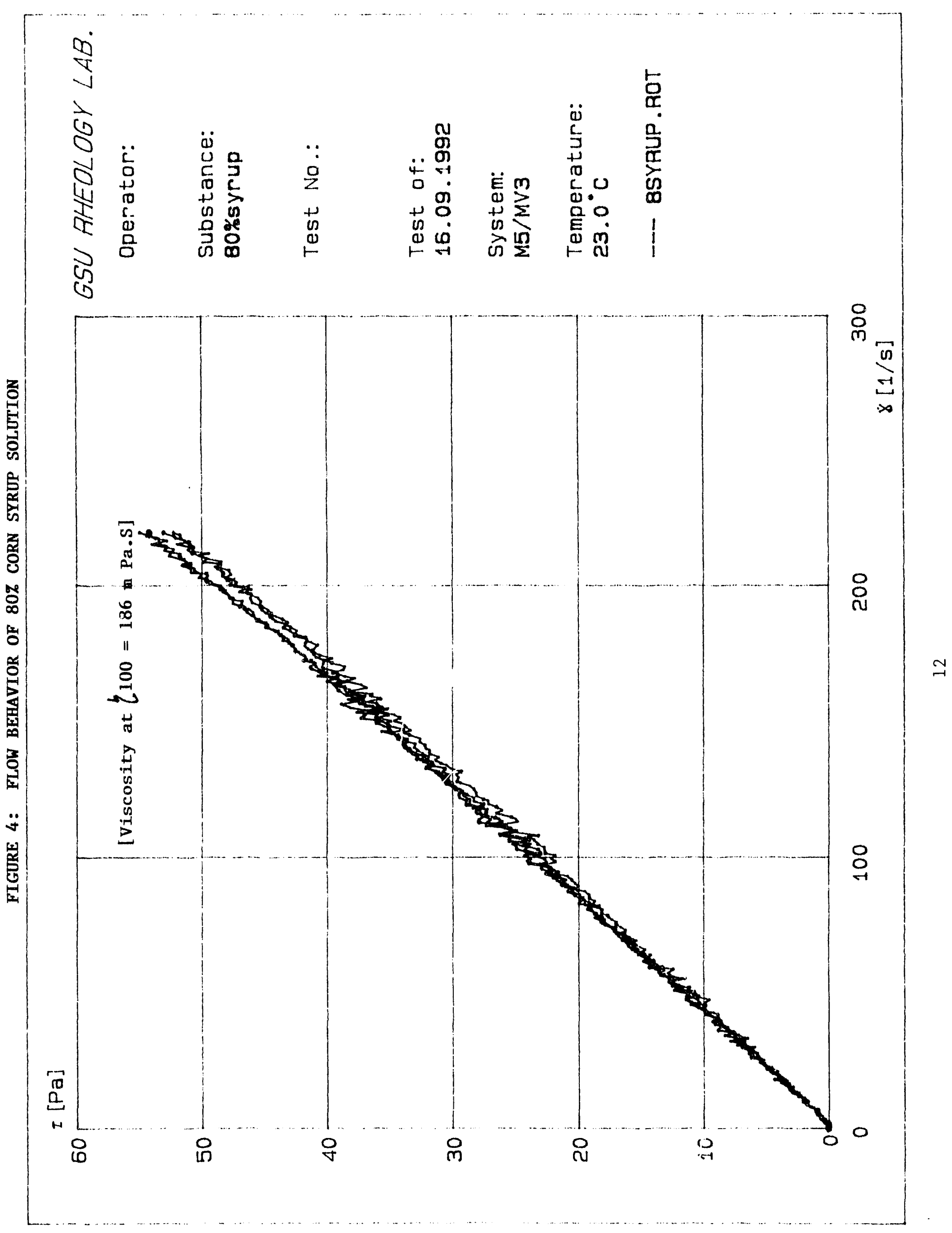




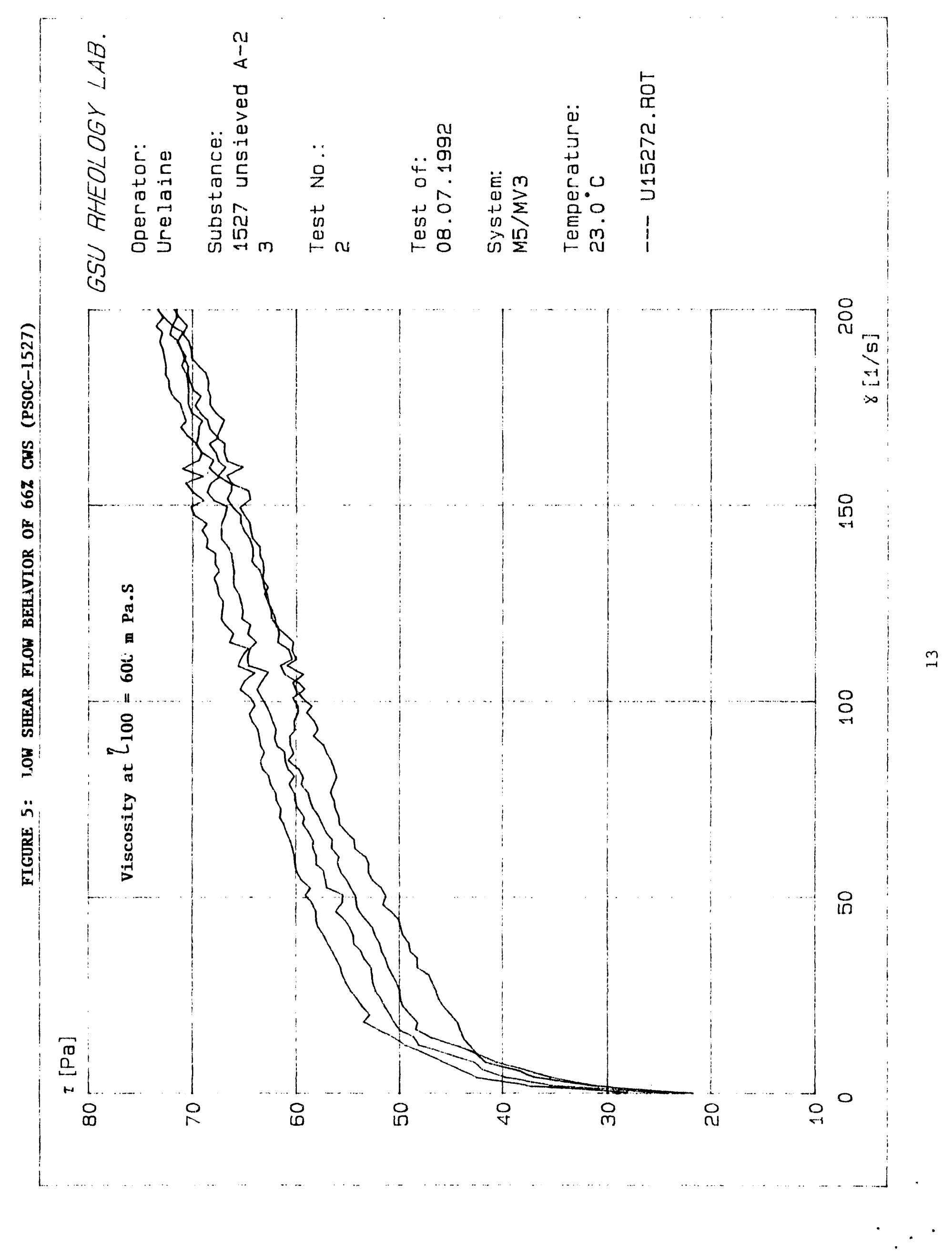




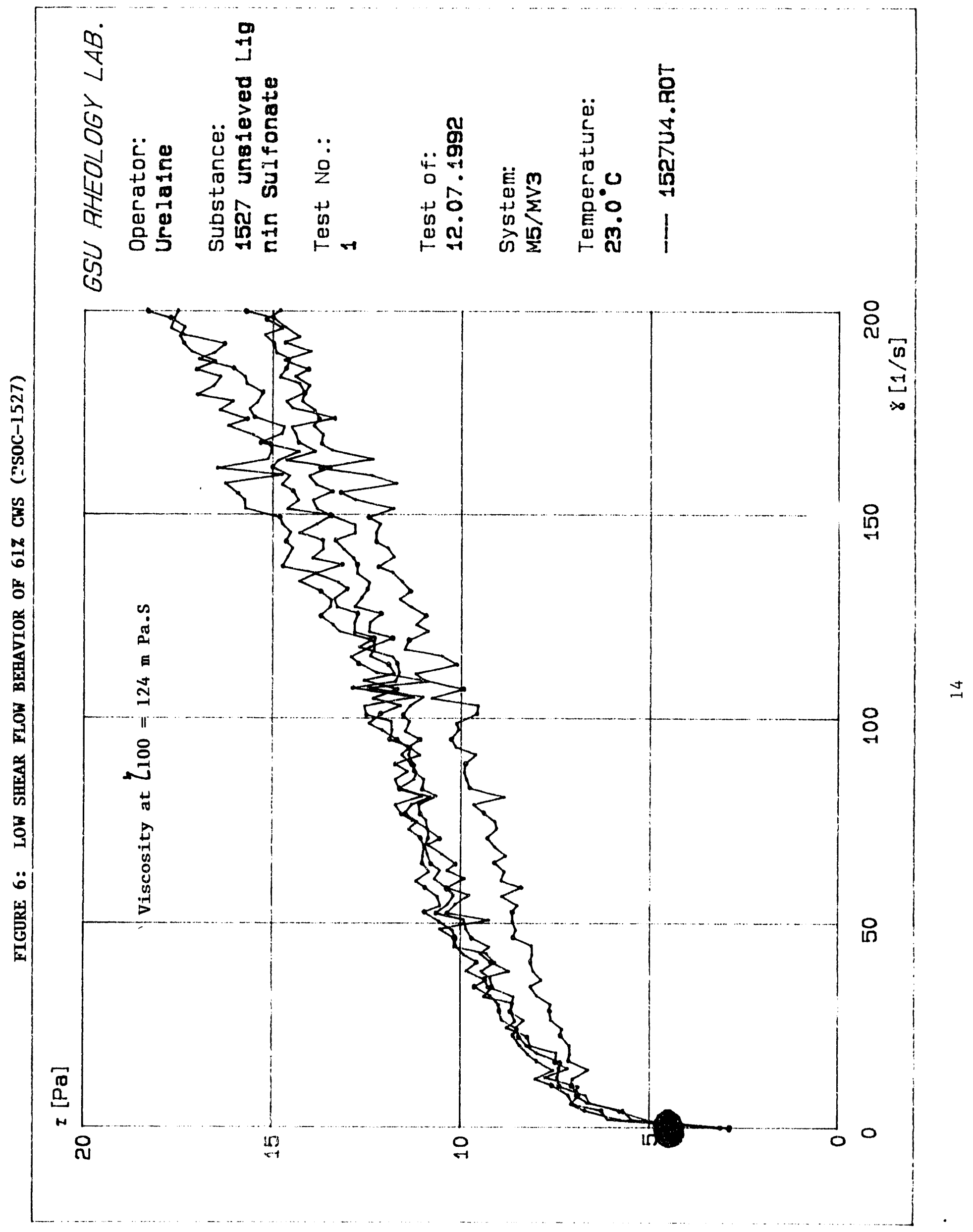


FIGURE 7: HLGH SHEAR FLOW BELAVIOR OF 61\% CWS (PSOC - 1527)

*

$A P \quad P \cap A R$

$1 \quad 9 \quad 11119$

$110 \mathrm{~m}$

IIVA-

$11,1969.19$

Mper at:ol

Samlate?

(a) 1 (ख)

$\therefore 110112 \%$

" $\quad 11111 \times 9$

$\because 10(1)$

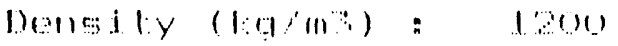

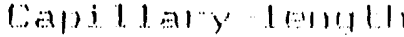

$1:$ i 10.81110

llumlie: : mes8006

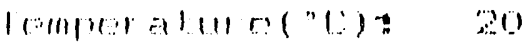

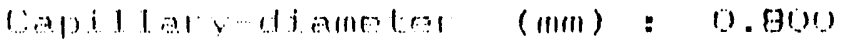

10 Tal. (Fa)

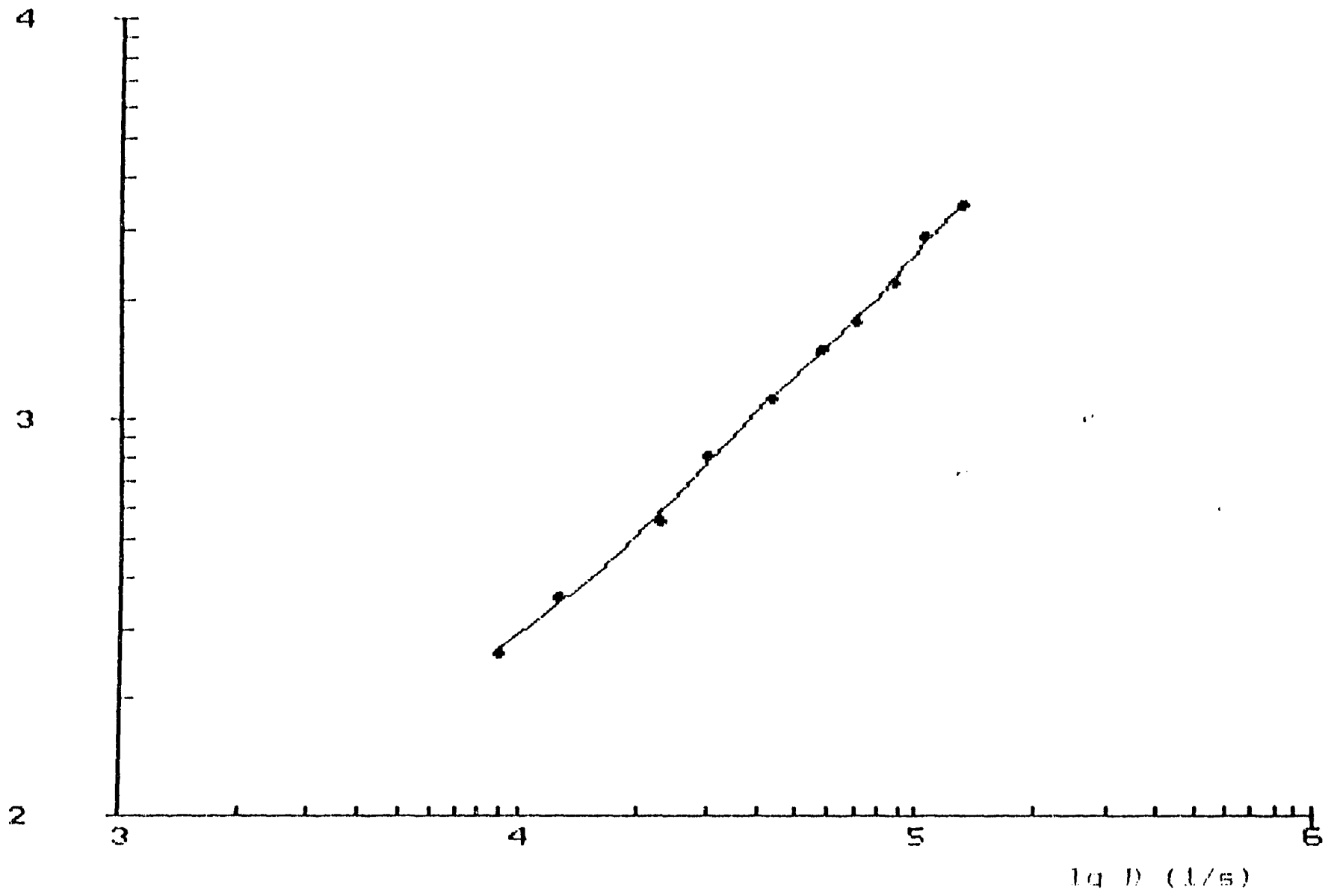


Frequency $(H z) \quad[.2-20] \quad$ Den. $(g / m 1)=1.2 \quad$ temp. ( $(c)=25.8$ Tube: Radius $(\mathrm{cm})=.0523$ Length $(\mathrm{cm})=8$

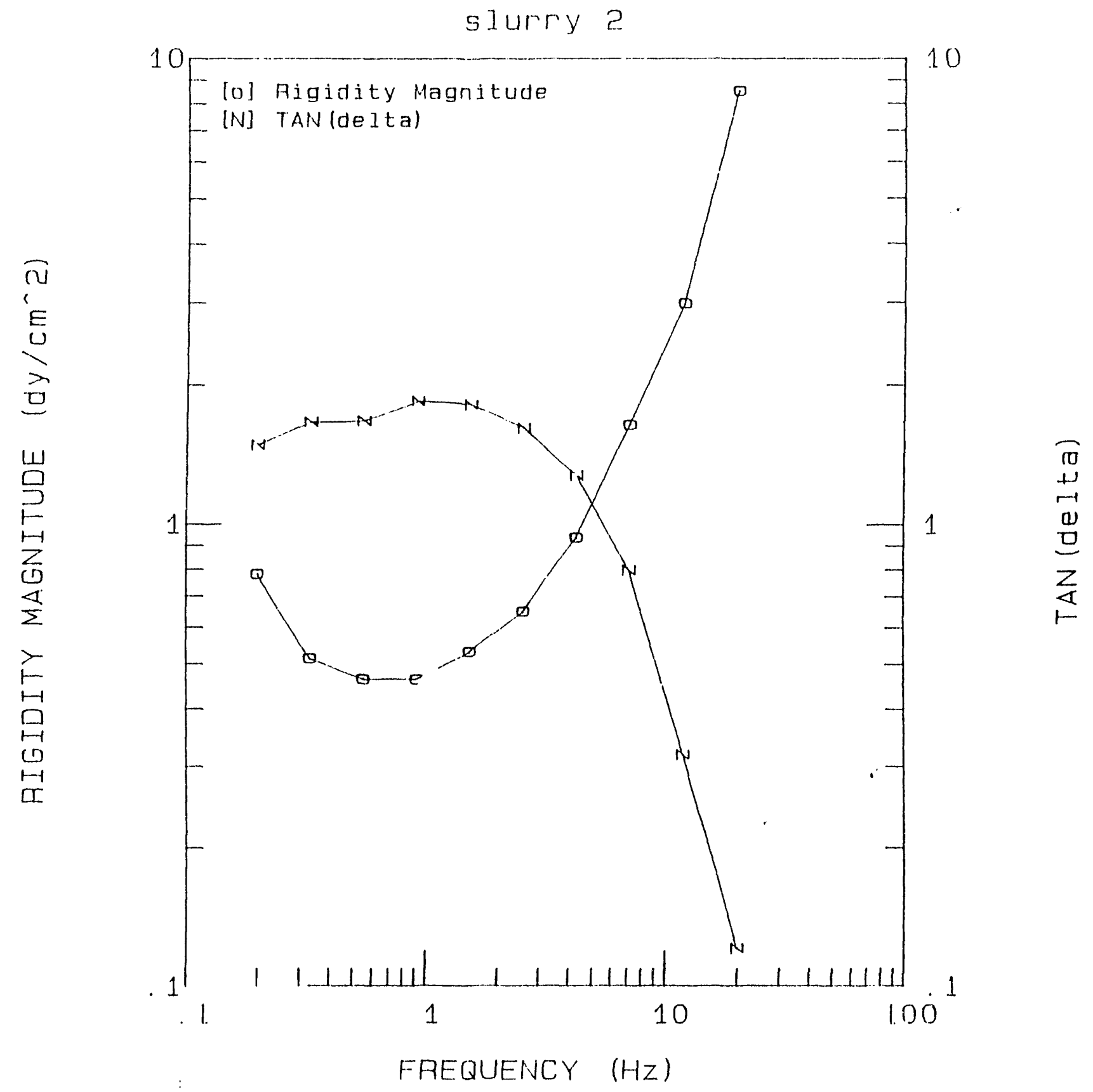



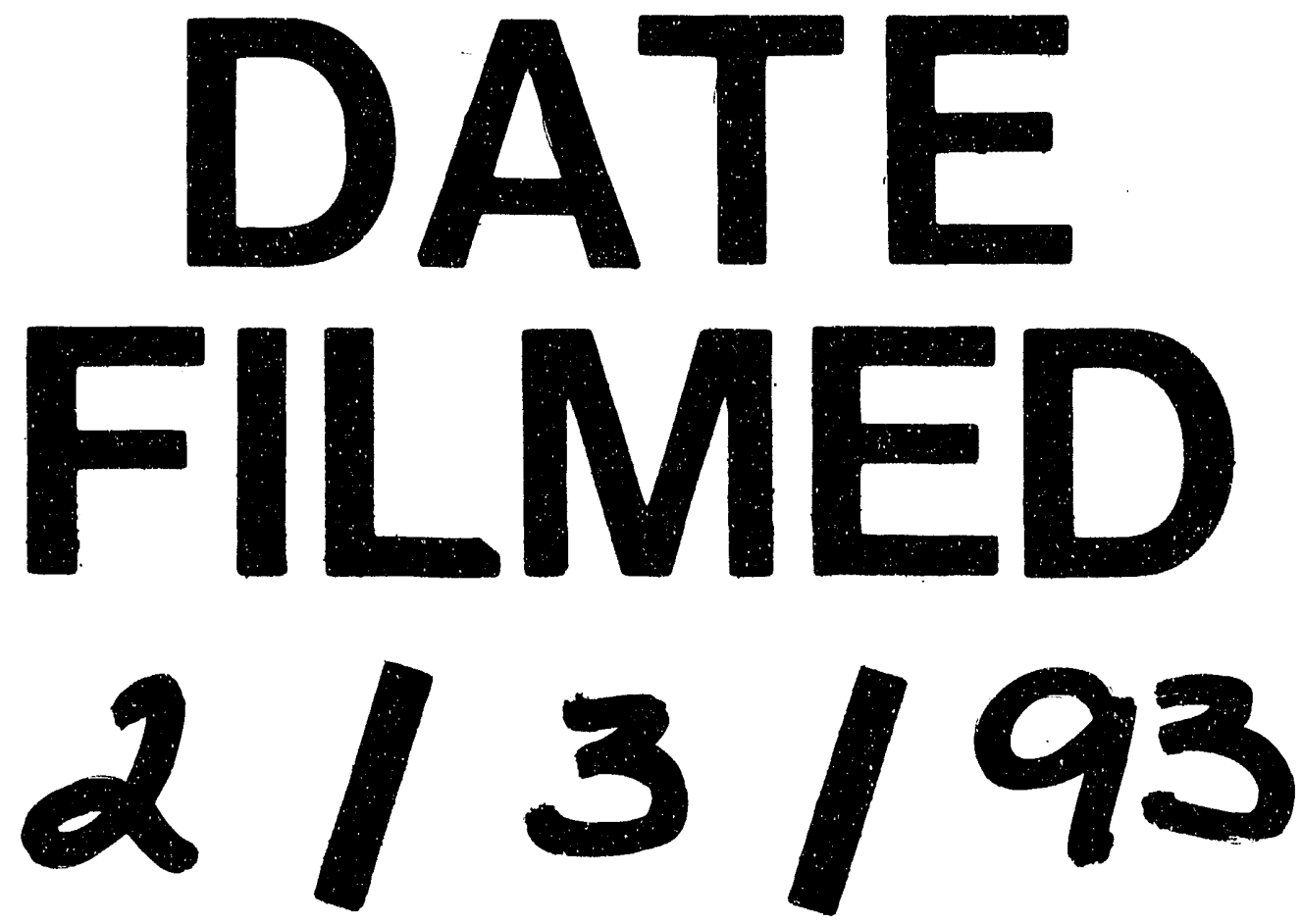
